games? Have cooking, sweeping, dusting, and other forms of work a reason for being in the kindergarten?

5. Should the teaching of form, number, color, and design be made subservient to the accomplishment of real or playful ends in which accomplishment problems are met that must be mastered, problems involving knowledge and use of facts of form, number, etc.

6. Typical programs to be worked out and presented for suggestion and criticism.

Child-study topics.-(I) The growth of motive. (2) Evolution of moral control. (3) Reasonings of children. (4) Typical interests of three-year-old and six-year-old children studied through their manual expression. (5) Typical interests of three-year-old and six-year-old children as found in their plays. (6) Children's lies. (7) Children's fears. (8) Co-operation in play. (9) Religious instincts. (I0) A kindergartner's bibliography of child study.

\title{
NATURAL SCIENCE.
}

\section{NATURE STUDY.}

W I L B U R. JACKMAN.

IT will be the aim in this course: (I) To make the student familiar with the organization of the landscape through a series of studies in the field. (2) To make a detailed study of the materials observed and collected on the field trips. This will be done chiefly indoors, $(a)$ by means of experiments in the laboratory, and $(b)$ through the use of the collections in the school museum. (3) To show the adaptations of this study to the various stages of child growth as represented in the grades. (4) To show the relation of nature study to other subjects in the curriculum ; namely, to history, literature, geography, number work, and all the arts-painting, drawing, modeling, making, reading, and writing. (5) To consider the proper forms for records which should be kept by the pupils who are engaged in nature study. Many of these points will be illustrated by work done by pupils in the Model School.

The lessons will be based upon a study of the landscape as an organism. It will be considered, first, as a whole, and then through each of its most important related parts. The study, therefore, will be an effort to determine the function that each portion of the landscape performs as a member of the whole, and 
to discover, as far as may be, the relationship of function to form. The lessons, consequently, will be included in the following groups :

I. A general survey of nature.

Living. Non-living. Interrelations of each. The phenomena of change. Development. Decay. Color. Form.

II. Plants.

Their function; function of different parts; illustrative experiments. Form as a whole and in each part. Constituents of plants; of different parts ; laboratory work. Work of the plant; application of number work.

III. Animals.

Adaptation to environment ; illustrated by a study of birds. Relation of form to function; illustrated by a study of the earthworm and the frog. Mechanics of animal life.

IV. Non-living nature.

(I) Physical aspects : Sunshine; its distribution. Effects of light and heat, diurnal and seasonal. Variation of sunshine; means of measuring; effects upon the atmosphere. Meteorology; appropriate records. Water in nature ; vapor, clouds, rain, dew, frost, snow ; appropriate measurements and means of concrete representation. Study of instruments of precision. (2) Soils: their structure and constituents; origin; nature of the various elements. Relation to plants; to animals. Laboratory experiments. Properties of minerals.

\section{Historic aspects of nature.}

Study of fossil plants and animals - ferns and fishes; what these ancient forms imply in world history. Ancient landscape pictures. Evidences of world changes at the present time.

VI. Pedagogic aspects of nature study.

Relation to history and literature; to number, reading, and writing. Expression through color-painting, drawing, modeling, and making.

VII. Nature study and training.

What is true observation? Observations of children compared with those of adults. Evils resulting from a lack of training in observation. The use of the imagination in nature study; necessary conditions; its relation to observation. Relation of nature study to the development of the will. The discovery and appreciation of law; its universal application. Nature study as a factor in character-building.

For detailed directions for laboratory work Nature Study for the Grammar Grades (Jackman) will be used. 


\section{ELEMENTARY FIELD WORK.}

I R A B. MEYER S.

The field work in science for the summer quarter is a general study of the type-topographic areas of the Chicago region. The work is.based upon a series of excursions to the lakeshore, lagoon and marsh area, sand dunes, ravine area (glacial till), ravine area (limestone), stream valley, etc. The study will include two considerations: (I) The investigation of each of these several areas with a view of becoming acquainted with their inorganic and organic content: mineral makeup; distribution of moisture; climatic influences; plant and animal life. (2) Field work in relation to grade teaching: aims and methods in field work; collecting materials and data ; care and arrangement of materials and data for class study; collected materials as permanent equipment (the school museum).

Suggestions in field work. - Elementary education must be thought of in terms of development. Environment is recognized as a potent factor in all organic, intellectual, or social development ; that the same general environment varies greatly in its influence on the residents of a region requires no argument. Interwoven with the study of materials, phenomena, and processes in all field work, topographic and industrial, is the more important study of that interrelation of the human being to environment which stimulates him to intelligent thought and action. Variation (change) is the starting-point of progress in the organic and social world. An area viewed as "everlasting hills" and never-changing valleys can have little influence as a stimulus in intellectual development. The same area, viewed as an ever-changing landscape, rendering necessary a constant readjustment of its plant and animal life, becomes infinite in its possibilities as a stimulus to thought and action. Every type of area may thus be looked upon as a unit of environment. Our problem is to bring ourselves into such relation to these units of environment that their latent possibilities may become potent influences in our lives.

The field study is from the standpoint of topographic change and the influence of this change upon the occurrence, form, and distribution of plant and animal life.

General directions.-Topography (for a detailed study of topography see Geography outline): Note the contour topography of the areas crossed and studied. The superficial materials of the several areas; their mineral make-up ; conditions under which this material entered the area. Toward what land contour are these separate areas tending? What forces are most active in the development of this contour? Are these forces constant or variable ? 
Plant life.- Note the general distribution of the vegetation in each of these areas; bird's-eye-view appearance of the area as to marsh, meadow, thicket, and woodland; the conditions determining or influencing this distribution. Make a list of the dominant plants in each area, that give the area its characteristic appearance.

Animal life.- Keep a list of the forms of animal life seen in each of these areas. Also note any signs of animal life - tracks, burrows, "calls, etc., where the living form is not actually seen. Observe as fully as possible the movement, food, and feeding habits, methods of foraging, protection, etc., of these animals.

\section{CONDITIONS INFLUENCING THE PLANT LIFE OF A REgION.}

During their growth and distribution plants are dependent upon certain conditions of temperature, air, moisture, light, and soil; variation in the nature and intensity of these factors greatly influence the plant life. The aim of field work is to observe conditions under which life exists, and to note the influence of these varying factors upon its occurrence, form, distribution, characteristics, and life-history.

I. Soil conditions. - (a) Nature of the soil in the various areas visited. (Collect samples and examine them. See Nature Study for Grammar Grades, by Jackman, p. 45.) (b) The part of the plant most closely related to the soil. (c) Soil conditions, physical and chemical, influencing plant growth. (d) The nature and cause of this influence. Examine plants with a view of determining depth of rooting, length of roots, whether thick or fibrous. Try to determine the conditions causing variation. Collect various soils for planting seeds, varying the compactness and moisture conditions of the soils, and noting the influence on the growing plants.

REFERENCE : King, The Soil.

2. Temperature.-Consider: The part of the plant most influenced by temperature during the heat of the summer. Conditions of plants at this season that may be attributed to the heat. The nature and cause of these heat influences. Are these conditions sufficient to account for the presence of prairies?

Note.-The influence of temperature on plant life is best studied in the spring and late fall. This phase of study must depend largely upon observations made during these seasons of the year.

3. Light.- (a) Consider the daily and seasonal variations in the light conditions of an area. (b) The part of the plant most intimately related to light. (c) The nature of the light influence upon plant growth and structure. (d) Variations in plant form and structure which may be considered as a response to the light stimulus. (e) Make a special study of the plant stem, 
form of top, arrangement of branches and leaves, in their relation to light. (Experiments on growing plants under varying light conditions, a study of the light influence on plant color and the accumulation of plant material.)

Moisture.-(a) Variations in the moisture content of the soils of the several areas. (Make an examination as directed in Jackman, Nature Study for Grammar Grades, p. 48.) (b) Parts of the plant intimately related to moisture, securing it, controlling its distribution through the plant. (c) Variations in plant structure and plant form that may be attributed to a variation in the moisture conditions. (d) Plant societies; their physiognomy as influenced by the variation of moisture. (Special experiments on plant transpiration, its control, the response of the root of plants to moisture stimuli.)

Plants as influenced by surrounding plants.

The interrelations of plant and animal life.

ANIMAL LIFE.

General Observations : Forms found in each topographic area : Dominant forms. Occasional forms.

I. Range.-(a) Forms unrestricted in their range. (b) Forms restricted to a particular part of the area. (c) Forms present because of a particular physiographic condition-permanent residents. (d) Forms attracted by seasonal food - temporary residents.

2. Movement.-Demands for movement ; range ; factors influencing movement. Organs of locomotion. (a) As adaptations to different media - land, air, water. (b) As affected by some peculiar aspect of the same medium. (c) As affected by some peculiarity of habit.

3. Food.-(a) Condition or nature of food - liquid or solid. (b) Character of food-vegetable, animal, mixed. Food, vegetable; locating food; kind of plant; part of plant; effect of injury upon plant; plants attempt to resist undue injury; length of time food is available and relation to life of animal. Food, animal: method of locating and capturing food. Influence on foraging habits of the animal.

4. Protection.- (a) Adaptations which enable individuals to maintain their position among these various forms. (I) Life-forms living in areas inaccessible to other forms. (2) Specially constructed homes or shields. (3) Special protective organs. (4) Secretions. (5) Cunning and swiftness. (6) Color protection. Without visible means of protection. (b) Adaptations enabling individuals to resist seasonal changes.

5. Homes.-(a) Living isolated in pairs, in colonies, animal societies. (b) Living in constructed homes. (c) Depending upon accidental shelter of holes, crevices, etc. $(d)$ Changing growing vegetation into homes-galls. (e) Songs, calls, etc.; purpose, methods of producing sound.

\section{SPECIAL STUDIES.}

A special study of our common animals, birds, batrachians, and mammals; their occurrence and habits as influenced by the conditions of their 
environment. Animal life in the schoolroom. The school museum in its relation to field work and class-room study.

NoTE.-Students should provide themselves with a small handbag, gamesack, or basket, wide-mouth 8-ounce bottle, etc., for collecting materials for schoolroom and experimental work.

REFERENCES : Salisbury and Alden, The Geography of Chicago and its Environs; Cowles, The Plant Societies of Chicago and Vicinity; Jordan, Animal Life; Coulter, Plant Relations; Comstock, Insect Life; Chapman, Bird Life; Jackman, Nature Study for Grammar Grades; Hodge, Nature Study and Life; "North Shore Area," THE Elementary School Teacher and Course of Study, Vol. II, No. 3. (See also "Primary Mathematics," ibid., Vol. II, No. I.)

\section{BEACH-POND-PRAIRIE AREA.}

(Seventy-first street and the lakeshore. Illinois Central train to south shore.)

\section{R A B. MEYERS.}

The conditions giving rise to a pond topography are varied. In the Chicago area three distinct origins may be recognized, each of which will be treated in its special area. (I) Pond formed by a sand-bar or beach line separating a portion of water from the main lake body; the first stage in this separation may be observed a short distance south of Edgewater; a second and a third stage may be seen in the area at Seventy-first street and the lakeshore. (2) Ponds formed by cut-offs in a stream; this is well developed along Thorn creek, between Thornton and Glenwood. (3) Ponds formed in the depressions on the irregular surface of the old glacial moraine, characteristic of the north shore area.

In each of these origins we recognize that there must have been a difference at the initial stages in the soil, water, and climate environment of each area, and that owing to these differences the story of the development of its life content must differ in several respects. A study of these ponds should aid us in securing some evidence of their origin, the changes they have undergone in reaching their present stage, the relation of these changes to their present soil, water, and life-content. Our special effort should be to collect evidences of change in the area, the nature and cause of this change, and its influence upon the past and present life of the area. The following outline is a consideration of the south shore area, with special reference to 
the origin and development of its beach-pond-prairie topography, and the influence of this development upon the past and present life content of the area.

\section{LAKESHORE.}

Acquaint yourself with the nature and distribution of the material along the lakeshore; the forces that are acting upon this material, and the part that each plays in determining its form and distribution. Examine the shore and the shallow water of the lake for evidence of plant life growing within the water border; conditions favorable and unfavorable to plant life in this border area. List the animal forms of which you see or detect evidences within or over this water area. Consider the conditions which invite the presence of these animals.

Observe the shore for evidences of birds or insect life ; try to determine the attraction offered by the shore to these forms of life. Examine the broad beach area, and list the plants found within it; observe their rooting, their foliage as to the character of the leaves and the comparative leaf surface; the influence of this vegetation on the moving sand. What determines the approach of this vegetation to the lake? What conditions in the area are most severe on plant life? What special adaptations enable the plants to survive these conditions?

\section{RECENT LAGOON.}

Try to determine the conditions that have given origin to this lagoon. Determine as fully as possible the plant and animal content of this body of water; list the vegetation growing on the lagoon border. By the aid of a trowel examine the sand along the border of the lagoon to a depth of a foot; note any variation in color, and account for this variation. Examine the sandbank west of this lagoon, and note any variation in the nature of its soil material. Make a special study of a vertical section of the old beach, and note any variation in character or coloring of the materials and evidences of stratification. Try to locate the surface area corresponding to these vertical layers. List the plant life seemingly characteristic of each special area. Note any evidences of animal life in the wooded area.

Materials to be collected for special class study: Soil from the sand area to determine its moisture content, and also from the woodland area. Soil from the sand area, the lagoon border, the vertical bank, and the woodland area, to determine its organic material. Plants from the sand area, to determine their rates of transpiration, and their moisture content.

THE SWAMP-PRAIRIE AREA.

Note the topography and character of the soil material of the swamp margin. The conditions which give rise to this topography. Try to determine whether the swamp has either decreased or increased in its original size. Using a piece of gas pipe, collect the soil to a depth of a foot or more from 
the bottom of the swamp. Compare this soil with similarly collected soil from the border and prairie area. (These soils should be tested as to the per cent. of organic matter entering into their composition. See Jackman, Nature Study for Grammar Grades, p. 45.) Consider the conditions which would cause such a soil formation, and the influence of these conditions on the area. Make a list of the plants of this swamp-prairie area; (I) those growing within the water border, floating plants, rooted plants; (2) plants found along the marsh border; (3) plants characteristic of the moist prairie. The structure and proportions of root, stem, and leaves in these plants, as compared with the plants of the sand area. Conditions favorable and unfavorable to plant life in these several areas. Try to determine the influence of these conditions on the occurrence, distribution, and life-histories of these plants. List the animals common to these several areas. Try to determine something of their distribution, their food and feeding habits, their life histories, their probable manner of entrance into the area. (Collect materials for experimental study as to constituents of the different soils, water content of these various plants and their comparative rates of transpiration. Collect animal life for stocking aquaria and insect cages to be used in detailed classroom study and in expression.) This area should form a basis for a summary of all the facts with which you are familiar as to the occurrence, distribution, life-habits, and histories of swamp animals and plants as influenced by environment.

References : Furneaux, Life in Ponds and Streams; Stokes, Aquatic Microscopy for Beginners; Needham, "Aquatic Insects of the Adirondacks," New York State Museum Report; Baker, The Mollusca of the Chicago Area; Needham and Hart, The Dragonflies of Illinois; Cowles, The Plant Societies of Chicago and Vicinity; Coulter, Plant Relations; Miall, The Natural History of Aquatic Insects; Elliott, North American Shore Birds; Geology Survey of Indiana, I899.

\section{HISTORY.}

\section{COURSE I. HISTORY IN THE ELEMENTARY SCHOOL.}

EMILY J. RICE.

\section{Fundamental theories.}

I. The school as a social institution. Adaptation of the curriculum to the needs of a progressive civilization.

2. Relation of subject-matter to experience.

3. Social occupations of the children. Standards by which these occupations should be measured.

4. Selection of historic material according to its value with reference to social work and activities.

5. Adaptation of subject-matter to experiences of children of different grades. Interest in social and industrial conditions; in political institutions. 